\title{
Inhibition of NF-кB, Bcl-2 and COX-2 Gene Expression by an Extract of Eruca sativa Seeds during Rat Mammary Gland Carcinogenesis
}

\author{
Salah Abdel-Rahman ${ }^{1 *}$, Nadia Shaban², Amany Haggag', Doaa Awad², Ahmad \\ Bassiouny $^{2}$, Iman Talaat ${ }^{3}$
}

\begin{abstract}
The effect of Eruca sativa seed extract (SE) on nuclear factor kappa B (NF- $\varkappa$ B), cyclooxygenase-2 (COX-2) and B-cell lymphoma-2 (Bcl-2) gene expression levels was investigated in rat mammary gland carcinogenesis induced by 7,12 dimethylbenz $(\alpha)$ anthracene (DMBA). DMBA increased NF- $x$ B, COX-2 and Bcl-2 gene expression levels and lipid peroxidation (LP), while, decreased glutathione-S-transferase (GST) and superoxide dismutase (SOD) activities and total antioxidant concentration (TAC) compared to the control group. After DMBA administration, SE treatment reduced NF- $x$ B, COX-2 and Bcl-2 gene expression levels and LP. Hence, SE treatment reduced inflammation and cell proliferation, while increasing apoptosis, GST and SOD activities and TAC. Analysis revealed that $\mathrm{SE}$ has high concentrations of total flavonoids, triterpenoids, alkaloids and polyphenolic compounds such as gallic, chlorogenic, caffeic, 3,4-dicaffeoyl quinic, 3,5-dicaffeoyl quinic, tannic, cinnamic acids, catechin and phloridzin. These findings indicate that SE may be considered a promising natural product from cruciferous vegetables against breast cancer, especially given its high antioxidant properties.
\end{abstract}

Keywords: DMBA - breast cancer - Eruca sativa - NF-kB - bcl-2 - COX-2 - qRT-PCR

Asian Pac J Cancer Prev, 16 (18), 8411-8418

\section{Introduction}

Breast cancer is the second most common cancer in the world. The most common types of breast cancer are ductal and lobular carcinoma (Zeeneldin et al., 2013). Environmental toxic agents especially polycyclic aromatic hydrocarbons (PAHs) are considered risk factors for breast cancer. PAHs result from incomplete combustion of coal, oil, petrol, wood, tobacco, charbroiled meats, garbage and other organic materials. Some of them are used in the industries of dyes, plastics and pesticides (Reynaud and Deschaux, 2006). They have carcinogenic and mutagenic effects since they alter the function of cell membranes and the associated enzyme systems. The most extensively studied PAHs are 7, 12-dimethylbenzo anthracene (DMBA) and benzo(a)pyrene. DMBA is an immunosuppressor and a powerful organ-specific laboratory carcinogen, it serves as a tumor initiator (Saha and Hait, 2012).

Several studies have suggested that phytochemical products could be a useful strategy to prevent the deleterious effects of xenobiotics including carcinogens and mutagens through the modulation of genes which control cell proliferation, cell cycle, apoptosis, signal transduction, oncogenesis and transcription regulation (Shaban et al., 2013). Rocket plant (Eruca sativa) is a member of the Brassica plant family. Eruca sativa has a wide spread medicinal use. It is used in Unani and Arab traditional medicine as a stomachic, diuretic, stimulant and for the treatment of scurvy. Epidemiological and experimental data provide strong evidence that Brassicaceae species and cruciferous vegetables inhibit tumorigenesis. Like other cruciferous vegetables, the preliminary phytochemical studies of rocket seeds revealed the presence of carotenoids, flavonoids, phenolics, vitamins and glucosinolates which metabolized into isothiocyanates (Melchini and Traka, 2010).

Nuclear factor kappa B $(\mathrm{NF}-x \mathrm{~B})$ is a nuclear transcription factor that regulates the expression of various genes, such as B-cell lymphoma-2 (Bcl-2) and cyclooxygenase-2 (COX-2), that involved in cell proliferation, adhesion, angiogenesis, apoptosis, cytoprotection, carcinoge-nesis, and inflammation. The activation and regulation of the expression of these gene products leading to cell cycle arrest, suppression of proliferation and induction of apoptosis (Escarcega et al., 2007). Apoptosis represents a physiological process for removing damaged or infected cells and maintaining tissue

${ }^{1}$ Department of Nucleic Acid Research, Genetic Engineering and Biotechnology Research Institute, City of Scientific Research and Technological Applications, ${ }^{2}$ Department of Biochemistry, Faculty of Science, ${ }^{3}$ Department of Pathology, Faculty of Medicine, Alexandria University, Alexandria, Egypt*For correspondence: salahmaa@gmail.com 
homeostasis (Shaban et al., 2013). During tumorigenesis, cancer cells develop the ability to avoid apoptosis through the upregulation of anti-apoptotic proteins and/ or downregulation of proapoptotic signalling pathways. Bcl-2 family of both pro- and antiapoptotic proteins are central regulators of apoptosis (Yip and Reed, 2008). COX-2 is an inducible enzyme, stimulated by cytokines, growth factors, oncogenes or tumour promoters during inflammation or malignancy. Overexpression of COX-2 has been detected in a number of tumors, such as breast, lung, pancreatic and colorectal cancers (Sobolewski et al., 2010).

The present study is to investigate the therapeutic effect of Eruca Sativa seed ethanolic extract against DMBA-induced mammary gland carcinogenesis through the study of gene expression of NF- $x \mathrm{~B}, \mathrm{COX}-2$ and $\mathrm{Bcl}-2$, as well as lipid peroxidation and antioxidant parameters. In addition, histopathological examination of breast and profile tests of liver and kidney were determined. Moreover, the characterization of Eruca Sativa seed ethanolic extract was studied.

\section{Materials and Methods}

\section{Eruca sativa seeds extract (SE) preparation}

Three kilograms of Eruca sativa seeds obtained from a market (Alexandria, Egypt) were grained. Grained seeds were soaked in $95 \%$ ethanol in an incubator shaker (150 $\mathrm{rpm}$ ) at $30^{\circ} \mathrm{C}$ for two days (Harborne, 1988). The extract was concentrated to dryness using rotary evaporator (Heidolph) to yield dried ethanolic extract, which was $12.89 \%(\sim 386.7 \mathrm{~g})$ of the starting material. Then the ethanolic extract was converted to powder using lypholizer (TELSTAR, Cryodos), which was $11 \%$ ( 330 g) of the starting material.

\section{Characterization of SE}

Qualitative phytochemical analysis. Phenols and tannins, flavonoids, saponins, glycosides, steroid, terpenoids and alkaloids were detected in SE which dissolved in water (1:1 w/v) (Harborne, 1973; Trease and Evans, 1989; Sofowora, 1993).

Quantitative phytochemical analysis. The ethanolic extract was analyzed for total phenolic contents (Taga et al., 1984), HPLC (phenolic compounds), total flavonoid contents (Zhishen et al., 1999), total triterpenoids (Bai et al., 2007), total alkaloids (Fazel et al., 2008) and total antioxidant capacities (Tyagi et al., 2010). Moreover, antilipid peroxidation assay (Ohkawa et al., 1979), reducing power (Oyaizu, 1986) and diphenyle- $\alpha$-picrylhydrazyl (DPPH) radical scavenging assay (Amarowicz et al., 2000) were evaluated.

\section{Experimental animal model}

Twenty-eight female Sprague-Dawley rats (weighing about 80-100 g at age 40 days) were obtained from Misr University for Science and Technology, Cairo, Egypt. Rats were examined for health status, housed and handled under ethical conditions according to the international rules of animal care. Rats were divided into four groups (seven rats/group). Experimental animal design was as follows: Control (C) group (administered orally with corn oil), DMBA (D) group (administered with DMBA dissolved in corn oil, $20 \mathrm{mg} / 100 \mathrm{~g}$ body weight) (Carroll et al., 2010), DMBA and SE (D-SE) group (administered with DMBA as group D and then the rats were treated orally with SE $(500 \mathrm{mg} / \mathrm{kg}$ body weight/day for four weeks)) (Behrens and Karber, 1970) and SE (SE) group (administered orally with SE only $(500 \mathrm{mg} / \mathrm{kg}$ body weight/day for four weeks)). Rats were palpated every day for mammary tumors. The cumulative number of tumor masses was calculated by each day's palpation of rats. Tumor volume (v) was determined by the following equation: $\mathrm{V}=(\mathrm{L} \times \mathrm{W} 2) / 2$, where $\mathrm{L}$ is the length and $\mathrm{W}$ is the width of the tumor. During treatment, animals were observed daily for signs of morbidity and mortality. Body masses were recorded initially, once weekly and at the end of the experimental period. At the end of the experimental period, feeding was stopped $12 \mathrm{~h}$ before dissection, then the rats were sacrificed and the mammary tissues of each animal were dissected and immediately put in RNA later and kept at $-80^{\circ} \mathrm{C}$ for the molecular study analysis.

\section{Quantitative real time polymerase chain reaction ( $q R T$ - PCR)}

RNAs extraction. From mammary gland rat's tissue, total RNA was isolated using Gene JET RNA Purification Kit (Thermo Scientific, USA). The extracted RNAs from different samples were quantified and qualified (purity) using NanoDrop Spectrophotometer. Finally, total RNAs samples were normalized (same concentration) to avoid any false increase in gene expression levels.

qRT-PCR. Using SYBER Green 1-step qRTPCR Kit (Thermo Scientific, USA), gene expression of BCl-2, NF-KB and COX-2 (target genes) and $\beta$-actin (reference gene) were quantified by RealTime PCR System (Thermo Scientific PikoReal) with the use of specific primers sequences (Forward/ Reverse) 5'-GGTGCCACCTGTGGTCCACCTG-3'/5'CTTCACTTGTGGCCCAGATAGG-3' for BCl-2 gene (Saleha, 2010), 5'-CTGGCAGCTCTTCTCAAAGC-3'/5'CCAGGTCATAGAGAGGCTCAA-3' for NF-kB gene (Yar et al., 2011), 5'-CTGTATCCCGCCCTGCTGGTG3 '/5 ' - T T GCGT TGATGGTGGCTGTCT T-3' for COX-2 gene (Rani and Kansal, 2011) and 5 ' - GTGGGCCGCTCTAGGCACCAA - 3' / 5' CTCTTTGATGTCACGCACGATTTC-3' for $\beta$-actin gene (Todorova et al., 2006; Saleha, 2010). qRT-PCR was performed in a reaction mixture of $10 \mu \mathrm{l}$ using $0.1 \mu \mathrm{l}$ verso enzyme mix, $5 \mu$ l 1-step QPCR SYBER mix (1X), $0.5 \mu \mathrm{l}$ RT-enhancer, $0.5 \mu \mathrm{l}$ forward and reverse primers (10 pm), 0-2.9 $\mu \mathrm{l}$ water (PCR grade) and 0.5-3.4 $\mu \mathrm{l} \mathrm{RNA}$ template $(50 \mathrm{ng})$. qRT-PCR program was applied as one cycle of cDNA synthesis at $50^{\circ} \mathrm{C}$ for $15 \mathrm{~min}$, one cycle of Thermo-start enzyme activation at $95^{\circ} \mathrm{C}$ for $15 \mathrm{~min}$ and followed by 40 cycles of denaturation at $95^{\circ} \mathrm{C}$ for 15 sec, annealing at $60^{\circ} \mathrm{C}$ for $1 \mathrm{~min}$ and extension at $72^{\circ} \mathrm{C}$ for $30 \mathrm{sec}$.

Antioxidant and oxidative stress profiles

One gram of the mammary gland tissue was 
Inhibition of $\mathrm{NF}-\mathrm{kB}$, bcl-2 and COX-2 Gene Expression by Eruca sativa Seed Extract in Rat Mammary Gland Carcinogenesis

homogenized in 5 volumes of cold $0.1 \mathrm{M}$ sodium phosphate buffer saline (PBS), $\mathrm{pH} 7.4$ using Teflon glass homogenizer at $4^{\circ} \mathrm{C}$. The total homogenate was centrifuged using cooling centrifuge at about $7000 \mathrm{rpm}$ for 20 min at $4^{\circ} \mathrm{C}$. The supernatant $(\mathrm{MH})$ was stored at $-20^{\circ} \mathrm{C}$ until used for the determination of malondialdhyde (MDA) level, superoxide dismutase (SOD) and glutathioneS-transferase (GST) activities (Nishikimi et al., 1972; Habig et al., 1974; Ohkawa et al., 1979). Moreover, total antioxidant concentration (TAC) was determined colorimetrically in serum (Nishikimi et al., 1972).

\section{Liver and kidney profile tests}

Alanine aminotransferase (ALT) activity, albumin, protein, urea and creatinine levels were determined in serum (Gornall et al., 1949; Reitman and Frankel, 1957; Doumas et al., 1971).
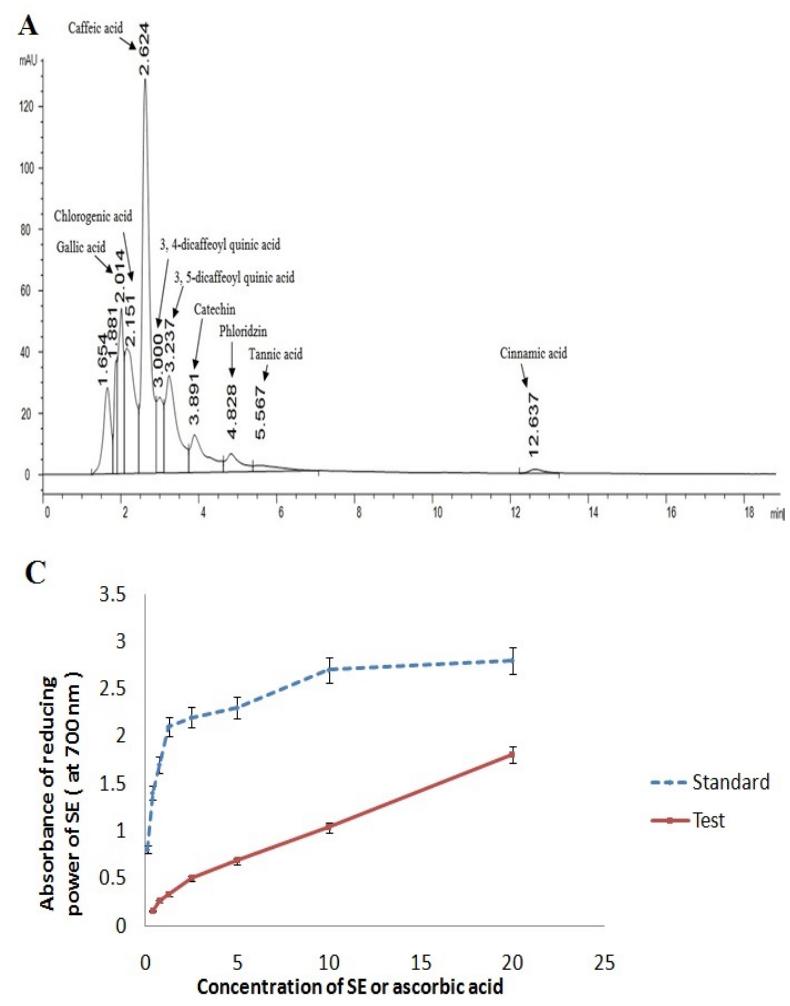

\section{Histopathological studies}

Mammary tissues were fixed in $10 \%$ formalin for 24 hour, washed with running water, dehydrated in ascending grades of alcohol $(70 \%, 80 \%, 95 \%$ and absolute alcohol) and cleaned by immersion in xylene followed by impregnation in melted paraffin wax in oven at $60^{\circ} \mathrm{C}$ for $1 \mathrm{hr}$. The specimens were embedded in paraffin and were left to solidify at room temperature. Using a rotary microtone, sections of $5 \mu \mathrm{m}$ thick were cut and were mounted on clean glass slides. Finally, the samples were stained with conventional hematoxylin and eosin (H\&E) stain for examination under light microscope for any histopathological changes.

\section{Statistical analysis}

Statistical analyses were performed using the statistical software, SPSS (Version 13). Results were presented as means $(\mathrm{X}) \pm$ standard deviation $(\mathrm{SD})$.
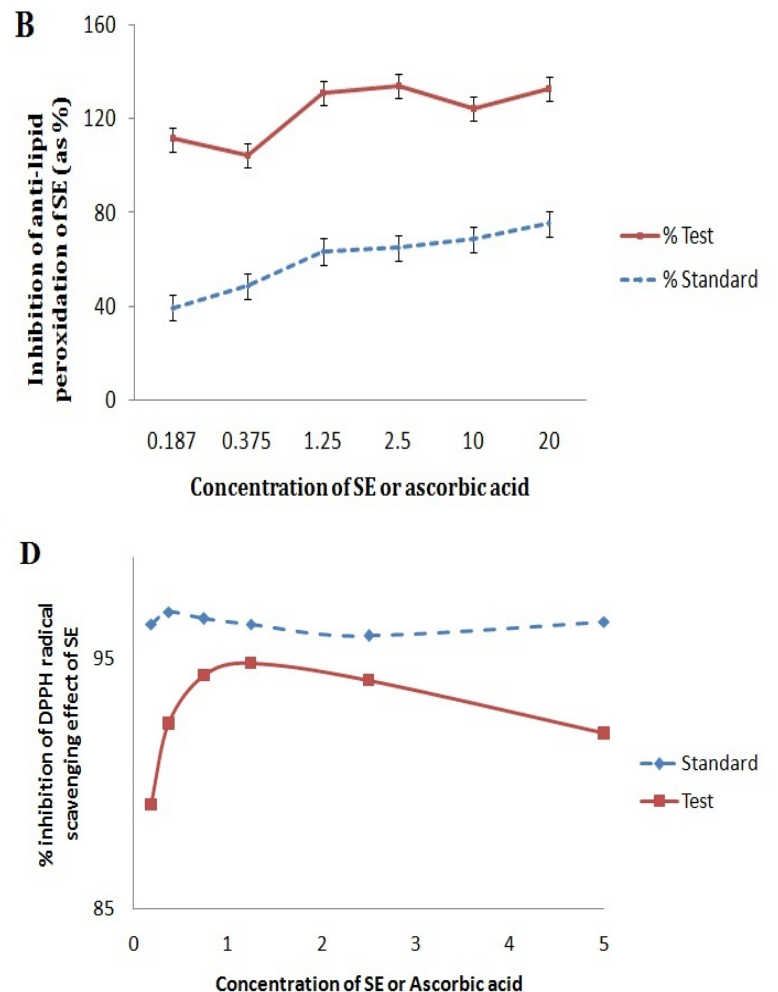

Figure 1. SE Characterization. (A). HPLC analysis of some phenolic compounds in SE (B). Anti-lipid peroxidation activity of SE (C). Reducing power of SE (D). DPPH radical scavenging activity of SE
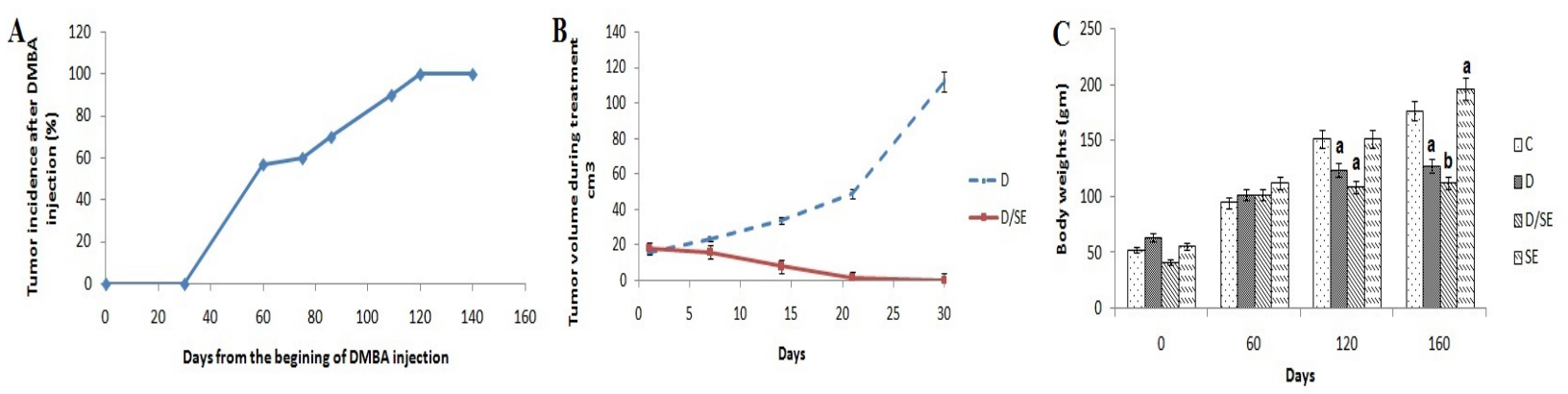

Figure 2. Genes Expression of Nf- $\varkappa \mathbf{b}, \mathbf{B c l}-2$ and COX-2 of Studied Groups. (A). Gene Expression level of Nf- $x \mathrm{~b}$ during the experimental period (B). Gene Expression level of Bcl-2 during the experimental period (C). Gene Expression level of COX-2 during the experimental period. Where, a: significant with $\mathrm{C}$ group, b: significant with $\mathrm{D}$ group, at $\mathrm{p}<0.05$. Group C: Control group; group D: rats injected with DMBA; group D-SE: rats injected with DMBA and then treated with SE; group SE: rats treated with SE only 


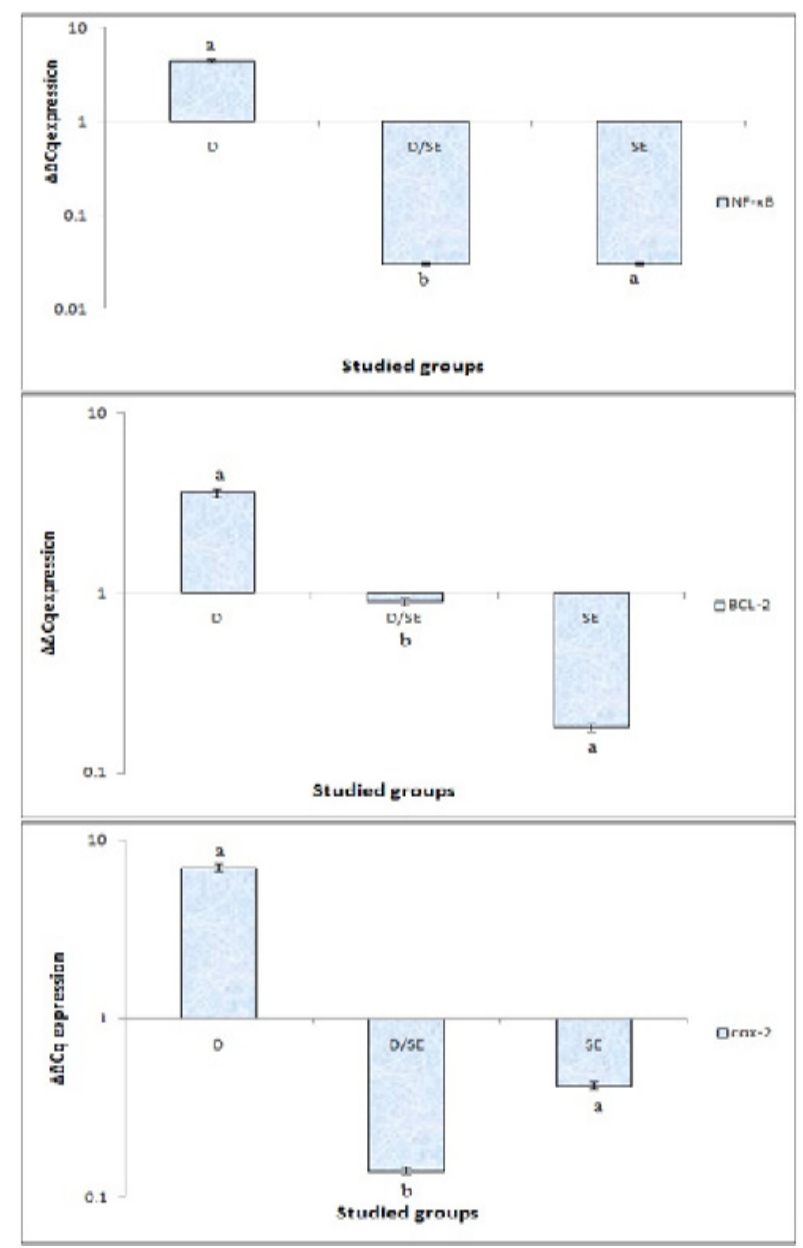

Figure 3. Genes Expression of $\mathrm{Nf}-\varkappa \mathrm{b}, \mathrm{Bcl}-2$ and $\mathrm{COX}$ -

2 of Studied Groups. (A). Gene Expression level of Nf- $x \mathrm{~b}$ during the experimental period (B). Gene Expression level of $\mathrm{Bcl}-2$ during the experimental period (C). Gene Expression level of COX-2 during the experimental period. Where, a: significant with $\mathrm{C}$ group, b: significant with $\mathrm{D}$ group, at $\mathrm{p}<0.05$. Group $\mathrm{C}$ : Control group; group D: rats injected with DMBA; group D-SE: rats injected with DMBA and then treated with SE; group SE: rats treated with SE only
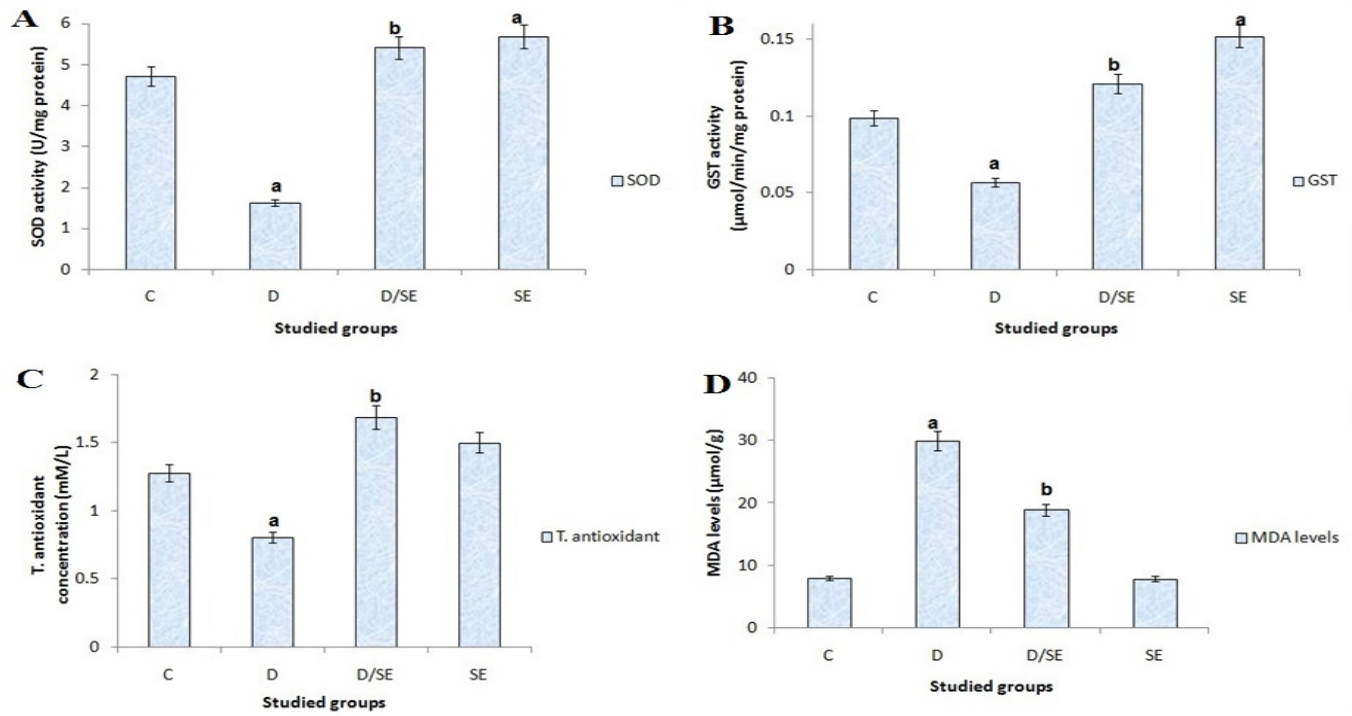

Figure 4. Alterations in the Levels of Lipid Peroxidation and Antioxidants of Studied Groups. (A) SOD activity (B) GST activity (C) Total antioxidant concentration (D) MDA levels. Where, a: significant with C group, b: significant with D group, at $\mathrm{p}<0.05$. Group C: Control group; group D: rats injected with DMBA; group D-SE: rats injected with DMBA and then treated with SE; group SE: rats treated with SE only 
Inhibition of NF- $\mathrm{kB}$, bcl-2 and COX-2 Gene Expression by Eruca sativa Seed Extract in Rat Mammary Gland Carcinogenesis

160 (after treatment by SE), body masses were decreased significantly by about $19 \%$ in D group compared to the C group. On the other hand, body masses were increased significantly by about $7 \%$ in D-SE group compared to the $\mathrm{D}$ group. While in SE group, body masses had a significant increase by about $19 \%$ compared to the $\mathrm{C}$ group.

\section{Gene expression of $\mathrm{NF}-\mathrm{kB}, \mathrm{Bcl}-2$ and $\mathrm{COX}-2$}

The expression levels of NF-kB, Bcl-2 and COX-2 genes in $\mathrm{D}$ group were significantly increased by about $341 \%, 261 \%$ and $603 \%$, respectively compared to the C group. While, the expression level in D-SE group was significantly decreased by about $99 \%, 75 \%$ and $100 \%$ respectively compared to the $\mathrm{D}$ group. The expression level of NF-kB, Bcl-2 and COX-2 genes in SE group was significantly decreased by about $97 \%, 82 \%$ and $57 \%$, respectively compared to the $\mathrm{C}$ group (Figure $3 \mathrm{~A}, \mathrm{~B}$ and C).

\section{Antioxidant and oxidative stress profiles}

SOD activity was decreased significantly in D group by about $66 \%$ compared to the $\mathrm{C}$ group. Whereas its activity

Table 1. Liver and Kidney Profile Functions

\begin{tabular}{|c|c|c|c|c|}
\hline \multirow[t]{2}{*}{ Test } & \multicolumn{4}{|c|}{ Studied groups } \\
\hline & $\mathrm{C}$ & $\mathrm{D}$ & D-SE & $\mathrm{SE}$ \\
\hline Albumin (g/dl) & $3.87 \pm 0.51$ & $2.40 \pm 0.36 \mathrm{a}$ & $4.04 \pm 0.14 b$ & $4.90 \pm 0.69 a$ \\
\hline$\%$ change from $\mathrm{C}$ & 0 & -38 & 5 & 27 \\
\hline$\%$ change from $\mathrm{D}$ & -- & 0 & 69 & -- \\
\hline Total protein (g/dl) & $6.95 \pm 1.31$ & $5.45 \pm 0.27 \mathrm{a}$ & $6.81 \pm 0.48 b$ & $6.96 \pm 0.26$ \\
\hline$\%$ change from $\mathrm{C}$ & 0 & -21 & -2 & 0.1 \\
\hline$\%$ change from $\mathrm{D}$ & -- & 0 & 25 & -- \\
\hline ALT (U/ml) & $30 \pm 1.91$ & $34 \pm 5.45$ & $31 \pm 3.43$ & $30 \pm 0.00$ \\
\hline$\%$ change from $\mathrm{C}$ & 0 & 13 & 3 & 0 \\
\hline$\%$ change from $\mathrm{D}$ & -- & 0 & -9 & -- \\
\hline Creatinine (mg/dl) & $0.69 \pm 0.39$ & $0.91 \pm 0.02 \mathrm{a}$ & $0.56 \pm 0.37 b$ & $0.58 \pm 0.16 \mathrm{a}$ \\
\hline$\%$ change from $\mathrm{C}$ & 0 & 32 & -19 & -17 \\
\hline$\%$ change from $\mathrm{D}$ & -- & 0 & -38 & -- \\
\hline Urea $(\mathrm{mg} / \mathrm{dl})$ & $26 \pm 5.5$ & $48 \pm 3.3 a$ & $21 \pm 5.6 b$ & $20 \pm 2.0 \mathrm{a}$ \\
\hline$\%$ change from $\mathrm{C}$ & 0 & 87 & -19 & -22 \\
\hline$\%$ change from $\mathrm{D}$ & -- & 0 & -57 & -- \\
\hline
\end{tabular}

*Values are expressed as mean \pm S.D. for six rats. Where, a: significant with C group, b: significant with D group, at $\mathrm{p}<0.05$. The positive values in the \% change mean there was an increase and the negative values mean there was a decrease. Group C: Control group; group D: rats injected with DMBA; group D-SE: rats injected with DMBA and then treated with SE; group SE: rats treated with SE only. ALT: Alanine aminotransferase
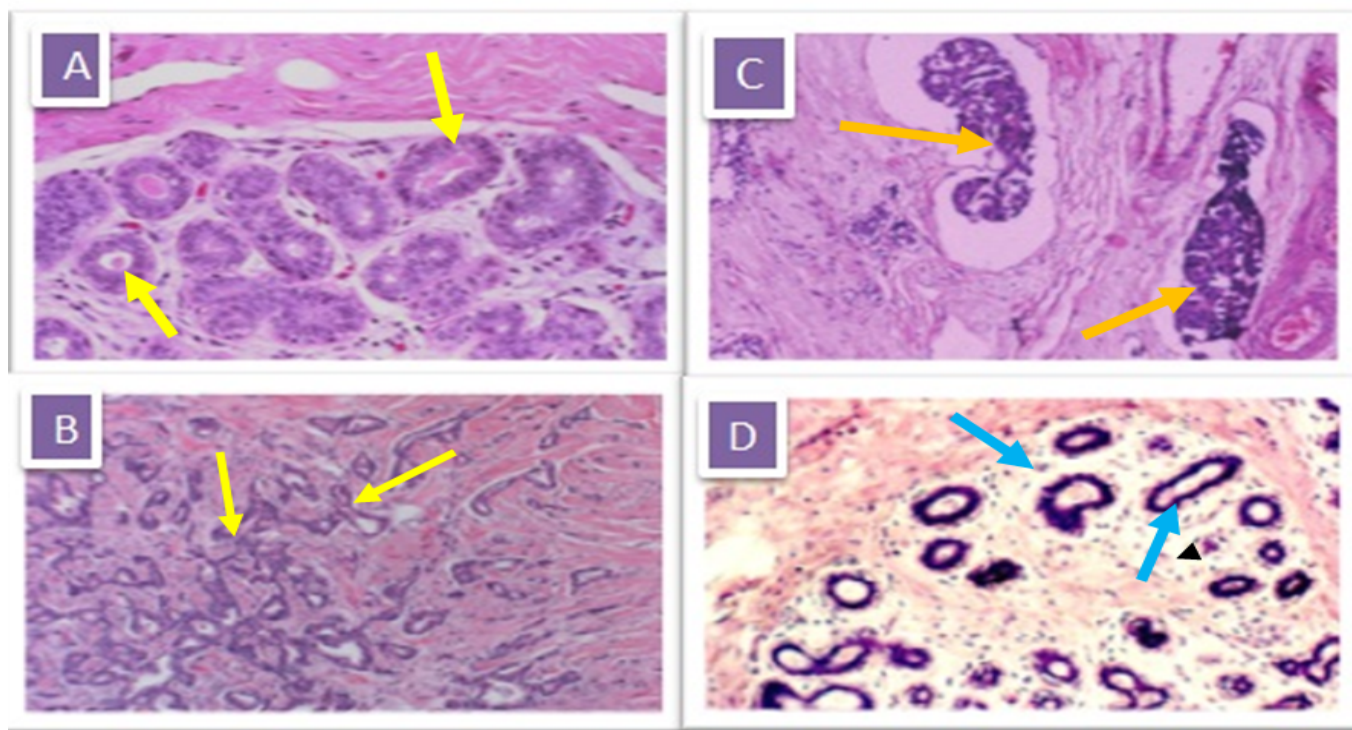

Figure 5. Histological Examination of Mammary Gland Tissue of Studied Groups. (A) C group (H\&E, x400) Examination of this group showed a dense collagenous tissue, blood vessels and islands of glandular tissue surrounded by dense fibrous and adipose tissue. The breast acini and tubules (arrows) are lined by inner epithelial layer (with dense cytoplasm) and outer myoepithelial layer (with clearer cytoplasm) (B) D group (H\&E, x200): Administration of rats with DMBA revealed a neoplastic growth made up of trabeculae, ducts, and nests of malignant ductal cells (arrows) having rounded to ovoid vesicular nuclei with prominent nucleoli and indistinct cell borders. The cytoplasm is abundant and eosinophilic. Mitotic figures are discerned. The stroma is desmoplastic and infiltrated by lymphocytic infiltrate mainly lymphocytes. Areas of necrosis are identified as well as foci of carcinoma in situ, whether the comedo form or the solid form. Foci of dystrophic calcification are noted in some sections (C) D-SE group (H\&E, x 100): In addition examination of mammary gland tissues of rats which treated with SE after DMBA administration revealed occasional nests of viable tumor cells left (arrows) (D) SE group (H\&E, x100): Administration of SE alone showed normal branched breast ducts (arrows) with normal distribution of fat tissue as control 
in D-SE group was increased significantly by about $235 \%$ compared to the D group. After SE administration SOD activity was increased significantly by about $21 \%$ compared to the $\mathrm{C}$ group (Figure 4A). GST activity was decreased significantly in $\mathrm{D}$ group by about $42 \%$ compared to the $\mathrm{C}$ group. While its activity in D-SE group was increased significantly by about $112 \%$ compared to the D group. SE administration significantly increased GST activity by about $54 \%$ compared to the $\mathrm{C}$ group (Figure 4B). TAC was decreased significantly in D group by about $37 \%$ compared to the $\mathrm{C}$ group. While its activity in D-SE group was increased significantly by about $109 \%$ compared to the D group. SE administration caused a non significant increase by about $17 \%$ compared to the C group (Figure 4C). The level of MDA of D group was increased significantly by about $275 \%$ compared to the C group. While its level in D-SE group was decreased significantly by about $37 \%$ compared to the D group. SE administration caused a non significant decrease by about $1.25 \%$ compared to the $\mathrm{C}$ group (Figure 4D).

\section{Liver and kidney profile functions}

Albumin and protein levels were significantly decreased in D group compared to the C group, while, their levels in D-SE group were significantly increased compared to D group. SE administration increased albumin level (significantly) and protein level (non significantly) compared to C group. ALT activity was nonsignificantly increased in D group as compared to C group, while, its level was decreased as compared to D group. SE administration had no affect on ALT activity as compared to $\mathrm{C}$ group. Creatinine and urea levels in $\mathrm{D}$ group were significantly increased compared to $\mathrm{C}$ group, while, their levels in D-SE group were significantly decreased compared to D group. SE administration significantly decreased creatinine level but nonsignificantly increased urea level compared to C group (Table 1).

\section{Histological examination of mammary gland tissues}

Examination of the $\mathrm{C}$ group showed a dense collagenous tissue, blood vessels and islands of glandular tissue surrounded by dense fibrous and adipose tissue. The breast acini and tubules are lined by inner epithelial layer with dense cytoplasm and outer myoepithelial layer with clearer cytoplasm (Figure 5A). Administration of rats with DMBA (D group) revealed a neoplastic growth made up of trabeculae, ducts, and nests of malignant ductal cells having rounded to ovoid vesicular nuclei with prominent nucleoli and indistinct cell borders. The cytoplasm was abundant and eosinophilic. Mitotic figures were discerned. The stroma was desmoplastic and infiltrated by lymphocytic infiltrate mainly lymphocytes. Areas of necrosis were identified as well as foci of carcinoma in situ, whether the comedo form or the solid form. Foci of dystrophic calcification were noted in some sections (Figure 5B). In addition, examination of mammary gland tissues of rats which treated with SE after DMBA administration revealed proliferated dilated breast ducts embedded into the surrounding fat tissue with no residual tumor tissue could be identified (Figure 5C). Administration of SE alone showed normal branched breast ducts with normal distribution of fat tissue as control (Figure 5D).

\section{Discussion}

In the present study, the results showed that the SE contains many antioxidant compounds. These compounds are phenolics, flavonoids, alkaloids and triterpenoid. HPLC analysis of phenolic compounds demonstrated the presence of gallic, chlorogenic, caffeic, 3,4-dicaffeoyl quinic, 3,5-dicaffeoyl quinic, catechin, phloridzin, tannic and cinnamic acids. Previous studies reported that SE also contains glucosinolates, carotenoids, flavonoids (quercetin, kaempherol and isohamnetin), vitamin $\mathrm{C}$, thiocyanates, isothiocyanates, glucoerucin, erysolin, sulforaphane, phenylethyl isothiocyanates and 4-methylthiobutyliso-thiocyanate (Melchini and Traka, 2010). All these compounds have an antioxidant activity.

The results of the present study also revealed that DMBA administration increased tumor incidence and tumor volume. Histologically, there was a neoplastic growth consisting of atipical pleomorphic epithelial cells with large hyperchromatic overlapped nuclei and dilated ducts containing inspissated secretions, a picture of adenocarcinoma. There was high invasion of tumor cells to the surrounding and adjacent stroma beside destruction of the cells. The biochemical results showed that MDA level was increased but GST, SOD activities and TAC were decreased in mammary gland tissues as compared to the $\mathrm{C}$ group. This indicates that DMBA increased lipid peroxidation (LP), inhibited antioxidant enzymes and induced oxidative stress (OS) as it generated some free radicals (FRs) such as epoxides and quinines which are metabolites of DMBA. These FRs could bind covalently to nucleophilic sites on cellular macromolecules leading to peroxidation of native membrane lipids (Farmer and Mueller, 2013). DMBA increased the gene expression levels of NF- $x \mathrm{~B}, \mathrm{COX}-2$ and $\mathrm{Bcl}-2$ compared to the $\mathrm{C}$ group, so, it induced proliferation and inflammation but suppressed apoptosis in the breast tissues. The elevation in NF- $x \mathrm{~B}$ expression level may be due to either mutation in genes encoding the NF- $x \mathrm{~B}$ transcription factors themselves or in genes that control NF- $x \mathrm{~B}$ activity such as I $x \mathrm{~B}$ genes. Also, some tumor cells secrete some factors (cytokines, FRs and oxidized LDL) which activate NF$\varkappa \mathrm{B}$. FRs, epoxides and quinines may activate $\mathrm{I} \varkappa \mathrm{B}$ kinase which phosphorylates $\mathrm{I} \chi \mathrm{B}$. The phosphoralated $\mathrm{I} \varkappa \mathrm{B}$ is ubiquitinated and degraded by the proteasome system leading to translocation of $\mathrm{NF}-x \mathrm{~B}$ into the nucleus inducing the expression of more than 200 genes (Wu and Kral, 2005). Blocking of NF- $x$ B causes tumor cell death, prevents their proliferation and increase their response to treatment (Escarcega et al., 2007). The elevation in COX-2 expression level may be due to the enhancement of transcription of the COX-2 gene by NF- $x$ B. This concur with previous studies which showed that $\mathrm{COX}-2$ over-expression is observed in $40 \%$ of breast cancers (Wu and Kral, 2005). Also, PGH2 (a product of COX2) is converted by prostaglandin E2 synthase to PGE2, that modulates cell proliferation, cell death, and tumor invasion in many types of cancer such as lung, breast and colon (Sobolewski et al., 2010). Moreover, increasing 
of Bcl-2 expression level indicates that the DMBA has a role in suppression of apoptosis which may be due to blocking of cytochrome c release from the mitochondria, thus preventing the activation of caspases (Yip and Reed, 2008). Also, elevation in Bcl-2 expression level may be related to increasing of $\mathrm{NF}-\varkappa \mathrm{B}$ gene expression. On the other hand, there was a decrease in levels of albumin and total protein with an increase in serum ALT level compared to the $\mathrm{C}$ group. This indicates that DMBA induced liver injury with a result of a decrease in protein synthesis, as well as, leakage of liver enzymes into blood circulation. The results showed that the levels of creatinine and urea in serum were elevated indicating the nephrotoxic effect of DMBA. This agree with previous results of (Bedi and Priyanka, 2012). Finally, the body masses of rats after DMBA administration at day 160 were decreased significantly compared to the $\mathrm{C}$ group.

Treatment with SE after DMBA administration caused a significant decrease in tumor incidence and tumor volume. Histopathological examination of rat mammary tissues revealed proliferated dilated breast ducts embedded into the surrounding fat tissue with no residual tumor tissue could be identified indicating the powerfull action of SE as an anticancer. The biochemical results showed that MDA level and the gene expression of NF- $x \mathrm{~B}$, COX-2 and BCL-2 were decreased compared to the rats administered with DMBA only (D group), conversely, GST, SOD activities and TAC were increased significantly. These results showed that SE acts as antioxidant, antiinflammatory and anticancer. Consequently, SE reduced OS, LP, inflammation and cell proliferation in breast tissues which were induced by DMBA and its metabolites. Moreover, SE activated the apoptosis by decreasing the gene expression of Bcl-2 leading to decrease the tumor incidence and tumor volume. This may be due to SE enhanced the detoxification of DMBA through induction of phase II drug metabolizing enzymes, reduction of carcinogen activation through suppression of cytochrome P450-dependent monooxygenases, promotion of apoptosis in cancer cells, perturbation in cell cycle progression and inhibition of angiogenesis and metastasis (Melchini and Traka, 2010). Also, the treatment with SE following DMBA improved the body masses at the day 160 compared to D group. Additionally, treatment with SE caused a significant elevation in total protein and albumin level with a significant decline in ALT activity in serum indicating the therapeutic role of SE against DMBA toxicity.

The antioxidative properties of polyphenolic compounds and flavonoids present in SE may arise from their action as hydrogen or electron donors, ability to stabilize unpaired electrons and scavenge ROS, terminate Fenton reaction, inhibit the $\mathrm{N}$-nitrosation reaction and prevent oxidative damage (Shaban et al., 2013). The previous studies showed that gallic, caffeic, tannic acids, erucin and erysolin, glucoerucin and isothiocyanates (components of SE) inhibit the negative effects of OS, LP and cell proliferation (Vasquez-Garzon et al., 2009). Moreover, glucoerucin and isothiocyanates induce phase II metabolizing enzymes (Melchini and Traka, 2010). Isothiocyanates can prevent the process of carcinogenesis by multiple mechanisms perturbing the three major steps initiation, promotion and progression, as well as, the later stages, angiogenesis and metastasis. The mechanisms of action include modulation of phase I, II and III detoxification, regulation of cell growth by induction of apoptosis with cell cycle arrest, induction of ROS-mechanisms and regulation of androgen receptor pathways (Melchini and Traka, 2010). These results are in agreement with previous studies concerning about treatment with SE after carbon tetrachloride (Alam et al., 2007). However, SE considers a promising natural product from cruciferous vegetables against breast cancer; especially our results confirmed that SE has high antioxidant and anti-carcinogenic properties.

\section{References}

Alam M, Kaur G, Jabbar Z, et al (2007). Eruca sativa seeds possess antioxidant activity and exert a protective effect on mercuric chloride induced renal toxicity. Food Chem Toxicol, 45, 910-20.

Amarowicz R, Naczk M, Shahidi F (2000). Antioxidant activity of crude tannins of canola and rapeseed hulls. Journal of the American Oil Chemists' Society, 77, 957-61.

Bai J, Hartwig JH, Perrimon N (2007). SALS, a WH2-domaincontaining protein, promotes sarcomeric actin filament elongation from pointed ends during Drosophila muscle growth. Developmental Cell, 13, 828-42.

Bedi PS, Priyanka S (2012). Effects of garlic against 7-12, dimethyl benzanthracene induced toxicity in wistar albino rats. Asian Journal of Pharmaceutical \& Clinical Research, 5, 170 .

Behrens B, Karber G (1970). Chemotherapy of Neoplastic Diseases Selli C, Ckhardt S and Nmeth L (eds.). Budapest, The publishing House of the Hungarian Academy, 37.

Carroll CE, Benakanakere I, Besch-Williford C, et al (2010). Curcumin delays development of medroxyprogesterone acetate-accelerated 7,12-dimethylbenz[a]anthraceneinduced mammary tumors. Menopause, 17, 178-84.

Doumas BT, Watson WA, Biggs HG (1971). Albumin standards and measurement of serum albumin with bromcresol green. Clin Chim Acta, 31, 87-96.

Escarcega RO, Fuentes-Alexandro S, Garcia-Carrasco M, et al (2007). The transcription factor nuclear factor-kappa B and cancer. Clin Oncol ( $R$ Coll Radiol), 19, 154-61.

Farmer EE, Mueller MJ (2013). ROS-mediated lipid peroxidation and RES-activated signaling. Annu Rev Plant Biol, 64, 42950.

Fazel S, Khosla V, Doll H, et al (2008). The Prevalence of Mental Disorders among the Homeless in Western Countries: Systematic Review and Meta-Regression Analysis. PLoS Med, 5, 225.

Gornall AG, Bardawill CJ, David MM (1949). Determination of serum proteins by means of the biuret reaction. $J$ Biol Chem, 177, 751-66.

Harborne JB (1973). Phytochemicals Methods. pp. 49-188.

Harborne JB (ed.) 1988. Phytochemicals Methods, Chapman and hall, London.

Melchini A, Traka MH (2010). Biological profile of erucin: a new promising anticancer agent from cruciferous vegetables. Toxins (Basel), 2, 593-612.

Nishikimi M, Appaji N, Yagi K (1972). The occurrence of superoxide anion in the reaction of reduced phenazine methosulfate and molecular oxygen. Biochem Biophys Res Commun, 46, 849-54.

Ohkawa H, Ohishi N, Yagi K (1979). Assay for lipid peroxides in animal tissues by thiobarbituric acid reaction. Anal 
Biochem, 95, 351-8.

Oyaizu M (1986). Studies on products of browning reaction prepared from glucosamine. Jpn J Nutr, 44, 307-15.

Rani R, Kansal VK (2011). Study on cow ghee versus soybean oil on 7,12-dimethylbenz(a)-anthracene induced mammary carcinogenesis \& expression of cyclooxygenase-2 \& peroxisome proliferators activated receptor-gamma in rats. Indian J Med Res, 133, 497-503.

Reitman S, Frankel S (1957). A colorimetric method for the determination of serum glutamic oxalacetic and glutamic pyruvic transaminases. Am J Clin Pathol, 28, 56-63.

Reynaud S, Deschaux P (2006). The effects of polycyclic aromatic hydrocarbons on the immune system of fish: a review. Aquat Toxicol, 77, 229-38.

Saha D, Hait M (2012). An ontological design: two stage mouse skin carcinogenesis induced By DMBA and promoted By croton oil. Asian J Res Pharm Sci, 2, 01-3.

Saleha YM (2010). Gene expression and histopathology alterations during rat mammary carcinogenesis induced by 7,12-dimethylbenz[a]anthracene and the protective role of Neem (Azadirachta indica) leaf extract. Journal of American Science, $\mathbf{6}$.

Shaban NZ, El-Kersh MA, El-Rashidy FH, et al (2013). Protective role of Punica granatum (pomegranate) peel and seed oil extracts on diethylnitrosamine and phenobarbitalinduced hepatic injury in male rats. Food Chem, 141, 1587-96.

Sobolewski C, Cerella C, Dicato M, et al (2010). The Role of Cyclooxygenase-2 in Cell Proliferation and Cell Death in Human Malignancies. International Journal of Cell Biology, 2010.

Sofowora A (ed.) 1993. Medicinal Plants and Traditional Medicine in Africa, Ibadan, Nigeria: Spectrum Books.

Taga MS, Miller EE, Pratt DE (1984). Chia seeds as a source of natural lipid antioxidants. Journal of the American Oil Chemists' Society, 61, 928-31.

Todorova VK, Kaufmann Y, Luo S, et al (2006). Modulation of p53 and c-myc in DMBA-induced mammary tumors by oral glutamine. Nutr Cancer, 54, 263-73.

Trease GE, Evans WC (1989). Pharmacognosy. In Eds Bailliere Tindall, London, pp. 45-50

Tyagi SN, Saxena RASRA, Patel BD (2010). In vitro antioxidant activity of methanolic and aqueous extract of Flacourtia indica Mer. American-Eurasian Journal of Scientific Research, 5, 201-6.

Vasquez-Garzon VR, Arellanes-Robledo J, Garcia-Roman $\mathrm{R}$, et al (2009). Inhibition of reactive oxygen species and pre-neoplastic lesions by quercetin through an antioxidant defense mechanism. Free Radic Res, 43, 128-37.

Wu JT, Kral JG (2005). The NF- $\varkappa$ B/I $\varkappa$ B signaling system: A molecular target in breast cancer therapy. Journal of Surgical Research, 123, 158-69.

Yar AS, Menevse S, Alp E (2011). The effects of resveratrol on cyclooxygenase-1 and -2 , nuclear factor kappa beta, matrix metalloproteinase-9, and sirtuin 1 mRNA expression in hearts of streptozotocin-induced diabetic rats. Genetics and molecular research : GMR, 10, 2962-75.

Yip KW, Reed JC (2008). Bcl-2 family proteins and cancer. Oncogene, 27, 6398-406.

Zeeneldin AA, Ramadan M, Gaber AA, et al (2013). Clinicopathological features of breast carcinoma in elderly Egyptian patients: A comparison with the non-elderly using population-based data. J Egyptian National Cancer Institute, 25, 5-11.

Zhishen J, Mengcheng T, Jianming W (1999). Research on antioxidant activity of flavonoids from natural materials. Food Chemistry, 64, 555-9. 